Journal of Contemporary Educational Research

Research Article

\title{
The Application and Research of College English Blended Teaching Mode Based on MosoTeach
}

Wei Yin

Jilin Engineering Normal University, Changchun 130052, Jilin Province, China

\begin{abstract}
Now it is the digital information age. With the maturity of mobile Internet technology and the increase of online education demand, mobile learning applications based on mobile Internet terminals have been vigorously developed and widely used. Blended English teaching based on mobile network technology has become an inevitable trend in College English teaching. The new teaching mode is student-centered and emphasizes the interaction between teachers and students. The implementation of personalized teaching mode is conducive to improving students' learning autonomy and innovation, it can improve the classroom teaching effect to a certain extent. At present, the post90 s college students are the pioneers of the Internet era, but also the trendsetters in the wave of mobile Internet. How to effectively apply the mobile learning platform such as MosoTeach to College English teaching is the core theme of this paper.
\end{abstract}

Keywords: MosoTeach; College English; Blended teaching mode

Publication date: September, 2020

Publication online: 30 September, 2020

*Corresponding author: Wei Yin, yinweigail@126.com

With the rapid development of China's economy, the society shows a strong demand for English talents, not only in quantity, but also in quality, level and type. However, due to the constraints of the overall social environment and the teaching system of higher education, College English education in China lags far behind the requirements of the situation. As a required course for college students, the effectiveness of classroom teaching plays an important role in the cultivation of talents and the improvement of educational ability. Therefore, the effective classroom teaching and research of College English has attracted extensive attention of the academic community. How to realize the effective classroom of College English has become an urgent problem to be solved.

In China, College English learners rely heavily on the classroom, that is the main place for students to learn English. This requires teachers to master effective classroom teaching strategies to improve classroom teaching effect and teaching quality. College English teaching should pay attention to the effective classroom teaching, to achieve efficiency and effect from the classroom, and extend the effect of College English teaching to the outside of the classroom. However, the current situation of College English classroom effectiveness in China is not optimistic. It is mainly manifested in the fact that classroom teaching ignores the cultivation of students' attitude, emotion, interest and learning strategies. Students can not form a subjective sense of value in English learning, which will affect the learning effect. Teaching objectives deviate from the needs of students, which will lead to the deviation of teaching behavior and teaching output in the direction, which leads to the unsatisfactory teaching effect. College English teachers should pay attention to the study and discussion of effective teaching, carry out necessary teaching knowledge reserve, and improve the skills of effective teaching. Only in this way can we implement effective teaching in College English class and improve the quality of College English teaching.

\section{The feasibility of College English blended teaching mode based on MosoTeach}

\subsection{Current situation of College English Teaching}

Based on the investigation and analysis of the current 
situation of College English Teaching in the author's University, there are several deficiencies in College English Teaching: firstly, students' foundation is weak and their interest in learning is low. Many students' English foundation is poor, their English level can't keep up with the teaching progress, they don't know how to learn and what to learn, which leads to the passive situation of "do not want to learn, do not want to learn". Secondly, the teaching mode of teachers is single and outdated. Many classrooms are still "what i say goes", "one word and one size fits all" of teachers, and the traditional grammar translation teaching method is used. Language learning is boring and there is little communication between teachers and students. Thirdly, mobile phones compete with teachers for classroom positions. As long as teachers' teaching supervision is not effective, students' distraction from playing mobile phones in class occurs frequently. Finally, the way of teacher evaluation is single and backward. In such a classroom teaching situation, students' learning efficiency can be imagined.

\subsection{Advantages of MosoTeach platform}

MosoTeach is a mobile teaching app based on the mobile Internet environment, which can meet the needs of teachers and students' classroom teaching interaction and timely feedback. It aims to stimulate students' autonomous learning on mobile devices, realize the timely interaction, resource push and assignment tasks between teachers and students, record students' learning behavior in real time through cloud services, and encourage students to learn through game based experience value. Teachers can praise and give experience value reward to realize process evaluation and personalized teaching. In essence, it constructs a visual, easy to operate learning system and learning mode for mobile learning. Teachers can create their own classes, invite students to join the class, publish various types of learning resources including pictures, documents and external network links according to teaching needs, and arrange diversified activities including homework, group tasks, voting, questionnaire, Q \& A discussion and testing. After joining the class, students can check in, view resources, participate in activities, etc.

\subsection{Blended teaching mode}

Blended learning (Franks, 2002) refers to a kind of blended learning, which is the combination of various teaching methods and teaching technologies. It aims to combine the advantages of classroom teaching with the advantages of online learning, so as to give full play to students' learning autonomy and flexibility. The introduction of College English blended teaching mode is a kind of teaching practice which can not only give full play to students' learning initiative, but also reflect the leading role of teachers. It can not only give full play to the advantages of traditional teaching mode, but also give full play to the advantages of network technology. Students are no longer simply passive receivers, but active information processors. Teachers have also changed from instillation of knowledge to instructors, supervisors and consultants of students' learning activities.

At present, almost all College English teaching classrooms can realize multimedia teaching, so the teaching mode is mainly a mixture of traditional teaching and multimedia teaching, and mobile phones can be used to assist learning in the class learning stage; in the extracurricular stage (before and after class), mobile technology plays a key role, and MosoTeach can make use of its own convenience to make students make full use of spare time, to provide students with ample preview and review in the integrated time, so as to be a useful supplement to classroom teaching. In this mode, the extracurricular learning part mainly reflects the advantages of mobile learning mode, so that students can use more spare time for extracurricular learning. The effect of extracurricular learning will directly affect the teaching in class, and the effect of the in-class teaching stage combining traditional teaching and multimedia teaching will affect the degree of students' investment in extracurricular in-depth learning.

\section{The implementation of College English blended teaching mode based on MosoTeach}

\subsection{Preview stage: teachers create situations to stimulate students' interest in learning}

In the blended teaching mode, the preview stage is mainly carried out on the mobile learning MosoTeach platform, which makes full use of the convenience of mobile learning, so that students can timely access to the information related to the classroom learning content, so as to carry out preview, so as to lay the foundation for teachers to teach according to their aptitude and students' active learning in the classroom learning stage. Each classroom teaching has a fixed 
content. Before class, the teacher will send the relevant background knowledge and cultural knowledge related to this topic to the students, and can push the video clips of the micro class to the students' learning client, and create a fixed learning situation for the students in advance. The purpose is to guide the students into the situation in advance, and strive for more time for the full and effective interactive communication in the classroom. With the help of the system notice pushed by MosoTeach, students can make clear their learning tasks, conduct autonomous learning, and give feedback by answering test questions. Teachers can check the progress and completion of students' preview. The degree of students' input and preview effect in this stage directly affect the starting point and effect of students' learning in the classroom learning stage.

\subsection{In-class learning stage: students experience situations, perceive language knowledge and practice language skills}

In the classroom teaching, we should break the traditional single teaching method and increase students' participation in class. Through brainstorming, students can think independently, speak and collide with each other. Teachers can label, praise and increase experience value of speeches. Random questions, so that all students have access to oral expression, is conducive to enhance the fairness of English teaching. In addition, to a certain extent, it reduces the students' fluke psychology of avoiding answering questions. Experience value can be set in each activity of students. Students can get different experience value after learning, which can stimulate students' sense of participation and achievement, and provide reference for the process assessment of the course. Teachers can also quickly and randomly generate papers through the blue ink client, and conduct random classroom tests by timing the time. The MosoTeach platform can automatically analyze the ranking and accuracy of each student's score, and automatically summarize the average score, average time spent, normal distribution chart and the accuracy rate of each question, so that teachers can more clearly understand the students' mastery of the teaching content. In the whole stage of classroom teaching, teachers should adopt Scaffolding Teaching strategy, gradually transition from the instructor to the instructor, monitor and other identities, transfer the main power of classroom learning to students, realize the interaction between teachers and students, students and students, so that students can experience the language in the situation, actively think, and then learn meaningfully.

\subsection{After class expansion: students deduce the situation, strengthen the sense of cooperation, and improve their language application ability}

Students have commanded knowledge of this unit through organized classroom learning. After class, the teacher designs the task situation, arranges the tasks that need to be completed by group cooperation, consolidates the learned knowledge in the task, and explores in the cooperation. MosoTeach platform can support random grouping or offline grouping. Students can submit audio, pictures, text assignments and videos according to the task content. Through the MosoTeach platform, we can carry out mutual evaluation between groups, and students can also get experience value reward when evaluating others' homework. The results of teachers' evaluation and students' mutual evaluation can be used as formative assessment in students' usual performance. Teachers should track the participation of students in the process of collaborative learning, communicate with the students with abnormal performance, and conduct individualized guidance after grasping the situation. Students can also ask questions to teachers through the MosoTeach platform to maintain the interaction between teachers and students anytime and anywhere.

\section{The practical effect of College English blended teaching mode based on MosoTeach}

The practice results show that mobile learning represented by MosoTeach has gained positive and positive evaluation among teachers and students. First of all, mobile learning conforms to the trend of the times, making good use of resources and saving resources. Using the mobile device on hand, the learning performance of the device can be brought into full play, while saving paper and reducing consumables, which is beneficial to environmental protection. Secondly, mobile learning helps to form a studentcentered English teaching mode. Its teaching design can be based on the needs of students, and promote English teaching with convenient and humanized design. Finally, mobile learning connects students and students, students and teachers from the network level, which helps to promote cooperative English learning among 
students, stimulate students' wisdom, and also makes teachers and students more closely connected, teaching feedback more timely, which is conducive to teachers' timely adjustment of teaching strategies and teaching content, and full service for students' learning needs.

\subsection{Mobile learning software has a high utilization rate to ensure students' learning time}

$95 \%$ students were able to use the software fluently on the mobile devices they used most, and $75 \%$ said they would like to open the software for learning. This provides a basic guarantee for mobile learning time. The vast majority of respondents think that the software is easy to operate and learn in "play", which is very novel and can stimulate interest in English learning. However, a small number of students think that frequent use of mobile phone or tablet computer for learning is easy to be interfered by other irrelevant content, which tests self-control and self-control.

\subsection{Mobile learning software plays the role of "assistant" to guide learning}

Mobile learning software plays the role of students' English learning assistant and plays a greater role in learning aids after class. The students interviewed said that the clear and intuitive column plate can guide them to view all kinds of learning tasks, obtain course notices and other information in MosoTeach, so as to make learning objectives more clear. With the help of MosoTeach push system notification, students can complete homework in time. Students can also use different devices to access and view the learning content saved in the cloud anytime and anywhere.

\subsection{Mobile learning simplifies the teaching process and improves the efficiency of classroom teaching}

Compared with the traditional roll call attendance method in the classroom, teachers can use the class software in the MosoTeach to open the limited time check-in in in the classroom, which can save valuable classroom teaching time. $70 \%$ students agree that "MosoTeach simplifies the learning process and improves English learning efficiency." The most typical example is the sending and receiving of homework. There is no need for traditional manual and paper supplies. Students do not need to wait for several weeks to get the teacher's correction and feedback information. In the bottom of the assignment submission interface, students can input questions directly, teachers can reply directly, and students can also see the answers of other students. It also facilitates the communication and contact between teachers and students. At the same time, it also keeps the students' achievement materials for a long time, which provides the basis for the formative evaluation. At the end of each unit, the teacher will test the words of the unit to test the students' mastery of the vocabulary of the unit.

\subsection{Mobile learning improves traditional classroom teaching and enhances democracy and fairness}

More than $80 \%$ students agreed that "MosoTeach voting and other functions make English classroom more democratic." In task-based teaching, teachers release multiple optional tasks, and students have more discourse power in the choice of learning tasks. More than $90 \%$ students agree that "the random roll call function of MosoTeach enhances the fairness of English class". Random roll call, all students have access to oral expression, is conducive to enhance the fairness of English teaching. In addition, to a certain extent, it reduces the students' fluke psychology of avoiding answering questions.

\section{Conclusion}

\subsection{The blended College English teaching mode supported by MosoTeach can promote teachers' teaching}

The teachers interviewed said that due to the support of mobile technology, the communication between teachers and students is more convenient. Therefore, before teaching in each unit, teachers can timely grasp the starting point of students' learning, so as to adjust the teaching content. According to the different starting point of each individual, different evaluation criteria are drawn up to help students achieve personalized development, and urge students to formulate learning objectives and learning plans in line with their actual situation.

Due to the deep integration of information technology and curriculum, teachers can use a variety of ways to teach knowledge in the teaching process, and the infiltration of cultural knowledge is more sufficient, so that students can deeply understand language knowledge in the context of social culture. The formative assessment in the blended listening and speaking teaching mode focuses not on the students' 
learning results, but on the learning process. Teachers can timely understand what progress students have made and what changes have taken place in the learning process, and take corresponding measures according to the different performance of individuals to promote or encourage their sustainable development. For the students who have no progress or retrogression, the teacher uses interviews and other forms to give them learning or psychological help and guidance. This evaluation method has achieved satisfactory results.In the process of preparing multimedia learning resources and carrying out Scaffolding Teaching, teachers have enriched cultural knowledge and teaching experience, which is rare in the past teaching.

\subsection{The blended listening and speaking teaching mode supported by MosoTeach can promote students' learning}

Through interviews with students, we find that after the implementation of the blended teaching mode, students' English learning attitude has become more positive, and there are positive reactions such as increased self-confidence, strong interest in learning and correct learning motivation.

Students generally recognize the way of extracurricular learning by using mobile devices. There is no obstacle for students to use mobile devices, and they think that the convenience provided by mobile learning can make them have more time to practice listening, especially this kind of practice is organized under the guidance of teachers, so both the frequency and the effect are more obvious than students' spontaneous learning. A lot of extracurricular practice will bring students something to say in class, and then their self-confidence will be enhanced.

The formative evaluation in the teaching process increases students' interest in learning. On the app of MosoTeach, for the test results of completed writing and other questions, students think that the evaluation given by the teacher is objective, and some of them think that the teacher's evaluation increases their learning motivation. The formative evaluation made by teachers in the teaching process and the enrichment of their learning portfolio in the learning process enable them to experience the happiness of the learning process and effectively promote and maintain their learning enthusiasm. Teachers' guidance and personalized comments promote their continuous reflection and enhance their enthusiasm for continuous progress.

The interaction and communication between teachers and students enhance the emotion. Students think that in this teaching mode, the relationship between themselves and teachers is closer, and the relationship between teachers and students has been sublimated. Students also said that they like to use mobile phones to communicate with teachers, feeling that the generation gap between teachers and students is gradually narrowing. Students get the development of emotional skills in the communication with teachers. The mobile phone, a life-oriented learning media, brings students a sense of belonging significantly higher than the "cold" computer, which reflects strong humanistic care in the mixed teaching mode.

The impact on students' learning strategies: on the one hand, the blended teaching mode makes full use of students' extra-curricular time, and transfers some repetitive listening and speaking exercises to extracurricular activities, so that the classroom teaching time is more valuable to use and learn how to learn. On the other hand, students show that they can use the scale for self-evaluation. Under the guidance of teachers, they often reflect on the strategies they use in the cognitive process, and summarize what strategies they have used and what shortcomings they have.

Students have changed in cooperative learning. In the formative evaluation of blended teaching mode, an important evaluation subject is peer evaluation. The cooperation between students is required in the interactive activities in the classroom and in the cooperative tasks after class. From the collected data, most of the college students as adults can make objective and pertinent evaluation on their peers, especially the group evaluation after group consultation and careful consideration, which has great reference value and guiding significance for the evaluated. The students in the interview expressed their willingness to cooperate with others in learning. Due to the support of mobile technology, the communication between students is more frequent and the interaction mode is more abundant, which promotes the emotional communication between students. Therefore, cooperation is not only to complete the task, students communicate and negotiate in English in cooperation, but also to develop their language communication ability and improve their comprehensive English application abilities.

\section{Discussion}

English teachers' professional skills also play a very 
important role in mobile learning, and directly affect effective teaching. On the one hand, English teachers should constantly improve their English professional quality and teaching skills. On the other hand, traditional English teachers should try their best to master new technologies and methods, update teaching concepts, creatively apply new technologies and new methods to college English teaching, actively select effective teaching modes, stimulate students' interest in English learning, and cultivate students' English application ability.

There are also some disadvantages in the use of MosoTeach platform. Sometimes students will use their class time to play mobile games, browse e-novels and other non learning content materials. Teachers should pay attention to the design of classroom activities, compact content, close connection, and more supervision and guidance. Students have to find someone else to do the test in class. In addition to strengthening supervision, teachers should encourage students to enhance their self-confidence and face their own learning ability. Some functions of MosoTeach are not perfect, such as the test question type does not support subjective questions at present.

Mobile Internet represented by MosoTeach is changing the education mode and will become the future development trend of educational informationization. Mobile Internet enables students to choose their own time and place for learning, which makes time fragmentation. As long as you want to learn, the network can provide learning resources at any time. The popularity of smart phones makes mobile teaching possible. The unlimited expansion of learning resources promotes the improvement of students' autonomous learning ability and resource acquisition ability. Colleges and universities should not only have advanced hardware measures, but also reasonably design the use of foreign language information resources, so that foreign language information resources can become a favorable tool for foreign language teaching. The future learning competition is the competition of learning efficiency, that is, the competition of acquiring knowledge and mastering skills per unit time. Higher education is also facing unprecedented challenges.

\section{References}

[1] Li SY. Application of Mobile Learning Method in English Undergraduate Teaching [J]. Journal of Anhui Institute of Electronic Information Technology, 2010 (6)

[2] Pan RY. Application of Mobile Learning in College English Teaching [J]. Open Education Research, 2013, 26 (6)

[3] Gao J. Application of Mobile Intelligent Terminal in College English Teaching [J]. Taiyuan City Vocational and Technical Journal, 2015 (8)

[4] Yang YW, Wang XG, Tao XR. Research and Design of Hybrid Learning Based on MosoTeach [J]. China Information Technology Education, 2016 (12)

[5] Meng TT. Reflections on the Application of MosoTeach in Teaching Process [J]. Asia Pacific Education, 2016. (15)

[6] $\mathrm{Hu} \mathrm{CH}$. Analysis on the Application Effect of MosoTeach in Practical English Teaching [J]. Journal of Yellow River Water Conservancy Vocational and Technical College, 2018 (1). 